Published online: 19 April 2018

\title{
OPEN Author Correction: Effect of compressibility and non-uniformity in flow on the scattering pattern of acoustic cloak
}

\section{Hyeonbin Ryoo (1) \& Wonju Jeon}

Correction to: Scientific Reports https://doi.org/10.1038/s41598-017-02143-y, published online 18 May 2017

This Article contains typographical errors in the Supplementary Information file.

In Equation S1,

$\frac{D \rho}{D t}+\nabla \cdot(\rho \mathbf{u})=0$

should read:

$\frac{D \rho}{D t}+\rho \nabla \cdot \mathbf{u}=0$

In Equation S8,

$\frac{D_{0} \mathbf{u}^{\prime}}{D_{0} t}+\left(\mathbf{u}^{\prime} \cdot \nabla\right) \mathbf{u}_{0}+\frac{\rho^{\prime}}{\rho_{0}^{2}} \nabla p_{0}+\frac{1}{\rho_{0}} \nabla p^{\prime}=0$,

should read:

$\frac{D_{0} \mathbf{u}^{\prime}}{D_{0} t}+\left(\mathbf{u}^{\prime} \cdot \nabla\right) \mathbf{u}_{0}-\frac{\rho^{\prime}}{\rho_{0}^{2}} \nabla p_{0}+\frac{1}{\rho_{0}} \nabla p^{\prime}=0$,

In Equation S13,

$\frac{D_{0} \mathbf{u}^{\prime}}{D_{0} t}+\frac{1}{\rho_{0}} \nabla p^{\prime}=-\left(\mathbf{u}^{\prime} \cdot \nabla\right) \mathbf{u}_{0}-\frac{\rho^{\prime}}{\rho_{0}^{2}} \nabla p_{0}$.

should read:

$\frac{D_{0} \mathbf{u}^{\prime}}{D_{0} t}+\frac{1}{\rho_{0}} \nabla p^{\prime}=-\left(\mathbf{u}^{\prime} \cdot \nabla\right) \mathbf{u}_{0}+\frac{\rho^{\prime}}{\rho_{0}^{2}} \nabla p_{0}$.

And finally,

'By using equation (S5), $\nabla p_{0} / \rho_{0}$ in the second term on RHS of equation (S13) is replaced by $\left(\mathbf{u}_{0} \cdot \nabla\right) \mathbf{u}_{0}$ '

Should read:

'By using equation (S5), $\nabla p_{0} / \rho_{0}$ in the second term on RHS of equation (S13) is replaced by $-\left(\mathbf{u}_{0} \cdot \nabla\right) \mathbf{u}_{0}$ ' 
(i) Open Access This article is licensed under a Creative Commons Attribution 4.0 International License, which permits use, sharing, adaptation, distribution and reproduction in any medium or format, as long as you give appropriate credit to the original author(s) and the source, provide a link to the Creative Commons license, and indicate if changes were made. The images or other third party material in this article are included in the article's Creative Commons license, unless indicated otherwise in a credit line to the material. If material is not included in the article's Creative Commons license and your intended use is not permitted by statutory regulation or exceeds the permitted use, you will need to obtain permission directly from the copyright holder. To view a copy of this license, visit http://creativecommons.org/licenses/by/4.0/.

(C) The Author(s) 2018 